\title{
Helicobacter felis-induced gastritis was suppressed in mice overexpressing thioredoxin-1
}

\author{
Kimio Kawasaki ${ }^{1}$, Akiyoshi Nishio ${ }^{1}$, Hajime Nakamura ${ }^{2}$, Kazushige Uchida ${ }^{1}$, \\ Toshiro Fukui ${ }^{1}$, Masaya Ohana ${ }^{1}$, Hazuki Yoshizawa ${ }^{1}$, Shinya Ohashi ${ }^{1}$, \\ Hiroyuki Tamaki ${ }^{1}$, Minoru Matsuura ${ }^{1}$, Masanori Asada ${ }^{1}$, Toshiki Nishi ${ }^{1}$, \\ Hiroshi Nakase ${ }^{1}$, Shinya Toyokuni ${ }^{3}$, Wenrui Liu ${ }^{4}$, Junji Yodoi ${ }^{4}$, \\ Kazuichi Okazaki ${ }^{5}$ and Tsutomu Chiba ${ }^{1}$
}

${ }^{1}$ Department of Gastroenterology and Endoscopic Medicine, Graduate School of Medicine, Kyoto University, Kyoto, Japan; ${ }^{2}$ Department of Experimental Therapeutics, Translational Research Center, Kyoto University Hospital, Kyoto, Japan; ${ }^{3}$ Department of Pathology and Biology of Diseases, Graduate School of Medicine, Kyoto University, Kyoto, Japan; ${ }^{4}$ Institute for Virus Research, Kyoto University, Kyoto, Japan and ${ }^{5}$ Third Department of Internal Medicine, Kansai Medical University, Osaka, Japan

\begin{abstract}
Thioredoxin-1 (TRX-1) is a redox-active protein involved in scavenging reactive oxygen species and regulating redox-sensitive transcription factors. TRX-1 is induced in various inflammatory conditions and shows cytoprotective action. We investigated the roles of TRX-1 in the host defense mechanism against Helicobacter felis (H. felis) infection. Transgenic (TG) mice overexpressing human TRX-1 and wild-type (WT) mice were orally inoculated with $\boldsymbol{H}$. felis. After 2 months, histology, oxidative damage, and gene expression of several cytokines, including macrophage inflammatory protein-2 (MIP-2), a murine equivalent to interleukin (IL)-8, in the gastric mucosa were investigated. Furthermore, the effects of TRX-1 on oxidative stress and neutrophil migration were studied both in vivo and in vitro. The gastric mucosa was thickened in $H$. felis-infected WT mice, but not in infected TRX-1-TG mice. Histologically, all $H$. felis-infected WT mice developed moderate-to-severe gastritis, whereas the development of gastritis was significantly suppressed in infected TRX-1-TG mice. Oxidative damage markers, 8-hydroxy-2'-deoxyguanosine and malondialdehyde, increased in the stomach of infected WT mice, but not TRX-1-TG mice. Upregulation of IL-1 $\beta$ and tumor necrosis factor- $\alpha$ gene expression in $H$. felisinfected TRX-1-TG mice was significantly lower than in WT mice. However, upregulation of MIP-2 and IL-7 was not different between the two groups. TRX-1 suppressed oxidative cytotoxicity and DNA damage, and inhibited neutrophil migration both in vivo and in vitro. The present study suggests that overexpression of TRX-1 suppresses $\boldsymbol{H}$. felis-induced gastritis by inhibiting chemotaxis of neutrophils and reducing oxidative stress. Laboratory Investigation (2005) 85, 1104-1117. doi:10.1038/labinvest.3700305; published online 20 June 2005
\end{abstract}

Keywords: Helicobacter, thioredoxin-1; gastritis; chemotaxis; oxidative stress

Helicobacter pylori (H. pylori) infection induces chronic atrophic gastritis, peptic ulcer, gastric cancer, and lymphoma. ${ }^{1}$ Many bacterial factors contribute to the development of $H$. pylori-related diseases, including urease-mediated acid tolerance, adherence factors necessary for colonization and maintenance of the infection, and virulence factors

Correspondence: Dr A Nishio, MD, PhD, Department of Gastroenterology and Endoscopic Medicine, Graduate School of Medicine, Kyoto University, 54 Shogoin-Kawahara-cho, Sakyoku, Kyoto 606-8507, Japan.

E-mail: anishio@kuhp.kyoto-u.ac.jp

Received 14 January 2005; revised 12 May 2005; accepted 16 May 2005; published online 20 June 2005 such as CagA and VacA that induce host cell damage. ${ }^{2-5}$

Oxidative stress induced by reactive oxygen species (ROS) has an important role in the formation of gastric mucosal injuries by various stressors including Helicobacter infection. ${ }^{6,7}$ There are several possible sources of ROS in Helicobacterinduced gastritis; infiltrating inflammatory cells (particularly neutrophils), gastric epithelial cells, and $H$. pylori itself. $H$. pylori eradication attenuates oxidative stress in human gastric mucosa. ${ }^{8}$ The redox state is finely tuned to preserve cellular homeostasis through the expression and regulation of oxidant and antioxidant enzymes. Mammalian cells have a complex network of antioxidants, 
such as catalase, superoxide dismutase (SOD), and glutathione peroxidase, to scavenge ROS. In addition to these enzymes, the members of a family of thiol-disulfide oxidoreductases act as cytoprotective antioxidants. Glutathione and thioredoxin (TRX) are the two most important redox-regulating molecules considered to regulate various cell functions, such as cell growth, apoptosis, and cytoprotection. ${ }^{9}$

TRX is a small multifunctional protein that contains a redox-active disulfide/dithiol within the conserved active site sequence; -Cys-Gly-Pro-Cys-. There are two forms of TRX, a cytosolic and nuclear form (thioredoxin-1 (TRX-1)) and a mitochondrial form (TRX-2). TRX-1 is induced by various types of stresses and protects cells from such stresses including viral infection, exposure to ultraviolet light, X-ray irradiation, and hydrogen peroxide $\left(\mathrm{H}_{2} \mathrm{O}_{2}\right) .{ }^{10}$ Moreover, TRX-1 scavenges ROS such as singlet oxygen, hydroxyl radical, and $\mathrm{H}_{2} \mathrm{O}_{2}$. In previous studies, we demonstrated that overexpression of TRX-1 in transgenic mice attenuated focal ischemic brain damage, ${ }^{11}$ adriamycin-induced cardiotoxicity $^{12}$ and thioacetamide- or lipopolysaccharideinduced acute hepatitis. ${ }^{13}$ It remains unclear, however, whether TRX-1 is involved in the host defense mechanism against Helicobacter-induced gastritis.

In the present study, we investigated the cytoprotective role of TRX-1 in $H$. felis-induced gastritis both in vivo using TRX-1-transgenic (TRX-1-TG) mice and in vitro using a murine gastric mucosal cell line, GSM06 cells.

\section{Materials and methods}

\section{Mice}

Wild-type (WT) C57BL/6 mice were purchased from Japan SLC Inc. (Shizuoka, Japan). The generation and maintenance of TRX-1-TG mice in which human TRX-1 complementary DNA (cDNA) was inserted between the $\beta$-actin promoter and its terminator were described previously. ${ }^{11}$ There were no differences in the expression of Mn-SOD, CuZnSOD, and glutathione peroxidase between WT and TRX-1-TG mice analyzed by immunohistochemistry and Western blotting. ${ }^{11}$ The presence of the TRX-1 transgene was confirmed by reverse transcriptionpolymerase chain reaction (RT-PCR) analysis prior to conducting the experiments.

\section{H. felis Infection}

H. felis (ATCC49179) used in the experiments was purchased from the American Type Culture Collection (Rockville, MD, USA). The bacteria were grown in brucella broth at a titer of $1 \times 10^{8}$ organisms $/ \mathrm{ml}$. The bacterial suspension was stored at $-80^{\circ} \mathrm{C}$ until use. TRX-1-TG and WT mice of the same age (8 weeks old) were inoculated with $0.5 \mathrm{ml}$ of bacterial suspension into the stomach using a steel catheter. ${ }^{14}$

\section{Cell Culture}

A murine gastric mucosal cell line, GSM06, which was established from transgenic mice harboring the temperature-sensitive simian virus 40 large T-antigen gene and can produce periodic acid-Schiffpositive glycoproteins, was obtained from Daiichi Pharmaceutical Co. (Tokyo, Japan). ${ }^{15}$ The cells were cultured in Dulbecco's-modified Eagle medium/ HamF12 medium (ICN Biomedicals, Irvine, CA, USA) containing $10 \%$ fetal bovine serum, $100 \mu \mathrm{g} / \mathrm{ml}$ streptomycin, and $100 \mathrm{IU} / \mathrm{ml}$ penicillin in $5 \% \mathrm{CO}_{2}$ at $33^{\circ} \mathrm{C}$ as described previously. ${ }^{16}$ For induction of endogenous TRX-1, GSM06 cells were cultured in 6-well plates and incubated with 0.1 or $1 \mathrm{mM} \mathrm{H}_{2} \mathrm{O}_{2}$ for $4 \mathrm{~h}, 100 \mathrm{ng} / \mathrm{ml}$ tumor necrosis factor (TNF)- $\alpha$ for $4 \mathrm{~h}$, or $1 \times 10^{8} \mathrm{H}$. felis/well at a multiplicity of infection (MOI) of 150 bacteria: 1 cell for 4 and $8 \mathrm{~h}$, respectively. Induced TRX-1 protein was detected by Western blot analysis.

\section{Western Blot Analysis}

Expression of murine and human TRX-1 was estimated by Western blot analysis using an antimouse TRX-1 (mTRX-1) polyclonal antibody or an anti-human TRX-1 (hTRX-1) monoclonal antibody (Redox Bioscience, Kyoto, Japan), respectively. Gastric epithelial cells were isolated and separated as described previously. ${ }^{17}$ Parietal cells were approximately $80 \%$ in parietal cell-enriched fraction and less than $10 \%$ in nonparietal cell fraction. The cells of each fraction were lysed with Laemmli buffer. GSM06 cells were collected by scraping and then lysed with Laemmli buffer. After heat denaturation, equal amounts of samples $(10 \mu \mathrm{g})$ were separated by sodium dodecyl sulfate-polyacrylamide gel electrophoresis and transferred to a polyvinylidene difluoride membrane (Pall Corporation, Pensacola, FL, USA). After blocking with Trisbuffered saline ( $\mathrm{pH} 7.4,10 \mathrm{mM})$ containing $5 \%$ skim milk/0.1\% Tween 20 , the membrane was incubated with a primary mouse anti-hTRX-1 monoclonal antibody or a rabbit anti-mTRX-1 polyclonal antibody and then with goat anti-mouse immunoglobulin (Ig) antibody or anti-rabbit Ig antibody conjugated with horseradish peroxidase (Cappel, Durham, NC, USA). Chemiluminescence was detected with ECL Western blotting detection reagents (Amersham Biosciences, Piscataway, NJ, USA).

\section{Histologic Examination}

At 2 months after inoculation, mice were killed under ether anesthesia. The stomachs were removed, fixed with $10 \%$ neutral buffered formalin, embedded in paraffin, and cut into $4-\mu \mathrm{m}$-thick sections. Sections were stained with hematoxylineosin for histopathology and May-Giemsa for assessment of $H$. felis colonization. ${ }^{18}$ The degree of 
gastritis was determined using the scoring system as described previously. ${ }^{19}$ Chronic inflammation, characterized by infiltration of mononuclear cells, was graded from 0 to 3 , where $0=$ no increase in the number of inflammatory cells, $1=$ slight infiltration of the lamina propria by lymphocytes and plasma cells, $2=$ moderately dense infiltration of the lamina propria by lymphocytes and plasma cells, $3=$ very dense lymphoplasma-cell infiltration in the lamina propria. Activity, characterized by presence of polymorphonuclear cells, was graded from 0 to 3 , where $0=$ no increase in the number of inflammatory cells, $1=$ scattered neutrophils in the lamina propria with no leukopedesis in the region of the gastric pits, $2=$ moderate number of neutrophils in the lamina propria with microabscess in the region of gastric pits, $3=$ extensive neutrophils in the lamina propria with obvious cryptitis. Atrophic changes were graded from 0 to 3 according to the loss of specialized cells $(0=$ no loss, $1=$ mild loss of parietal and chief cells, limited within half of the corpus glands, $2=$ moderate loss of parietal and chief cells, diffusing to more than half of the corpus glands, $3=$ severe loss of parietal and chief cells throughout the whole gastric body).

\section{Assessment of $\boldsymbol{H}$. felis Infection}

H. felis infection was assessed by serum levels of anti- $H$. felis antibodies and the amplification of H. felis DNA in the gastric tissue. An enzyme-linked immunosorbent assay (ELISA) was used to measure serum levels of anti- $H$. felis antibodies as described previously. ${ }^{20}$ The normal upper limit was based on the results obtained from normal mice (mean +2 s.d.). Expression of Helicobacter-specific genes in the gastric mucosa was identified by PCR. Extracted DNAs from the stomach of infected WT and TRX-1TG mice were amplified with the Helicobacter genus-specific primers as described previously. ${ }^{21}$ Briefly, DNA was extracted from the gastric tissue using ISOGEN Reagent (total DNA isolation reagent; Nippon Gene, Tokyo, Japan). Two primers were designed from the regions of the $16 \mathrm{~S}$ ribosomal RNA gene that are conserved among the members of Helicobacter genus: H276 forward primer, 5'-CTAT GACGGGTATCCGGC-3'; and H676 reverse primer, 5'-ATTCCACCTACCTCTCCCA-3'. Samples were heated at $94^{\circ} \mathrm{C}$ for $9 \mathrm{~min}$ and subjected to 35 cycles consisting of denaturation $\left(94^{\circ} \mathrm{C}, 30 \mathrm{~s}\right)$, primer annealing $\left(50^{\circ} \mathrm{C}, 1 \mathrm{~min}\right)$, and extension $\left(72^{\circ} \mathrm{C}\right.$, $1.5 \mathrm{~min}$ ) in a Gene Amp PCR system 9600 (PerkinElmer, Boston, MA, USA).

\section{Immunohistochemistry}

Immunohistochemical staining was performed on $10 \%$ neutral buffered formalin-fixed, paraffin-embedded sections. After rehydration and blocking of endogenous peroxidase activity with $0.3 \% \mathrm{H}_{2} \mathrm{O}_{2}$ for
$30 \mathrm{~min}$, the sections were incubated with a primary anti-mTRX-1 polyclonal antibody, a primary antihTRX-1 monoclonal antibody or a primary mouse monoclonal antibody against 8-hydroxy-2'-deoxyguanosine (8-OHdG; Japan Institute for the Control of Aging, Shizuoka, Japan) at $4^{\circ} \mathrm{C}$ overnight. Immunoreactivity of anti-mTRX-1 antibody and anti-hTRX-1 antibody was visualized with the VECTASTAIN Elite ABC kit (Vector Laboratories, Burlingame, CA, USA) and diaminobenzidine. For immunohistochemistry of 8-OHdG, M. O. M. biotinylated anti-mouse IgG antibody (Vector Laboratories) was used as the secondary antibody for 10 min according to the manufacturer's instructions. The secondary antibody was visualized by the same method as for mTRX-1, described above. For immunocytochemistry of 8-OHdG, GSM06 cells were cultured on eight-well culture slides (BIOCOAT Collagen I Cellware, Becton Dickinson, Bedford, MA, USA) and incubated with $100 \mu \mathrm{M} \mathrm{H}_{2} \mathrm{O}_{2}$ plus $30 \mu \mathrm{M} \mathrm{Fe}^{2+}$ for $3 \mathrm{~h}$ in the presence of 0,10 , and $50 \mu \mathrm{M}$ recombinant human TRX-1 (rTRX-1, Redox Bioscience). After fixation with 95\% ethanol, microwave irradiation in $10 \mathrm{mM}$ citrate buffer and permeabilization with $0.1 \%$ Triton-X, endogenous peroxidase activity of the sections was inactivated with $0.3 \% \mathrm{H}_{2} \mathrm{O}_{2}$. Then, immunostaining for 8-OHdG was performed as described above and specimens were subjected to densitometric analysis. Immunocytologic data (expressed as 8-OHdG index) were analyzed as previously described. ${ }^{22}$ The following equation was used for the quantitation of immunocytologic data: 8 -OHdG index $=\Sigma[(X$-threshold $) \times$ area $\left.\left(\mu \mathrm{m}^{2}\right)\right] /$ total cell number, $X>$ threshold, where $X$ is the staining density indicated by a number between 0 and 254 on the gray scale.

\section{Lipid Peroxidation Assay}

The concentration of lipid peroxides, malondialdehyde (MDA) and 4-hydroxyalkenals (HAE) derived from the peroxidation of polysaturated fatty acids and related esters, in the gastric mucosa was assessed colorimetrically using Lipid Peroxidation Assay Kit (Calbiochem, La Jolla, CA, USA). After removing the stomachs of each group, the whole stomach was homogenized in $20 \mathrm{mM}$ PBS containing $5 \mathrm{mM}$ butylated hydroxytoluene to prevent sample oxidation. The supernatant was used to assay MDA and HAE levels and protein concentration according to the manufacturer's instructions. The levels of MDA and HAE were measured at $586 \mathrm{~nm}$ using a spectrophotometer and expressed as $\mu \mathrm{M} / \mathrm{mg}$ protein.

\section{Quantitation of Cytokine Message}

Total RNA was extracted from the whole stomach in each group using ISOGEN reagent (Nippon Gene). Extracted RNA preparations were digested by Deoxyribonuclease I (Invitrogen, Carlsbad, CA, 
USA) for RNA purification and reverse transcribed with MultiScribe reverse transcriptase (Applied Biosystems, Foster City, CA, USA). The resultant cDNAs (50 ng/reaction mixture) were analyzed for expression of interleukin-1 $\beta$ (IL- $1 \beta$ ), TNF- $\alpha$, IL-7, and macrophage inflammatory protein-2 (MIP-2) genes using TaqMan real-time PCR assay with an ABI Prism 7700 sequence detection system (Applied Biosystems). The oligonucleotides and TaqMan fluorogenic probes were as follows: IL-1 $\beta$ (forward, 5'-CGTTCC CATTAGACAACTGCACTA- $3^{\prime}$; reverse, $5^{\prime}$-TGTTGGT TGATATTCTGTCCATTGA-3'; probe, 6FAM-AGCCTC GTGCTGTCGGACCCATATG-TAMRA); IL-7 (forward, 5'-TGAAGACCCAGCGCAAAGTA-3'; reverse, 5' -CGC TCTGGCTTTGCCATAA- $3^{\prime}$; probe, 6FAM-CACTGAG ATGGAAAGTCTGGAATGCTTGCT-TAMRA); MIP-2 (forward, 5'-AAAGTTTGCCTTGACCCTGAAG-3'; reverse, 5'-CAGTTAGCCTTGCCTTTGTTCAGT-3'; probe, 6FAMCCCCCTGGTTCAGAAAATCAT CCAA AAG-TAMRA). The primers and probes for TNF- $\alpha$ were purchased from Applied Biosystems. Reaction mixtures were incubated for $2 \mathrm{~min}$ at $50^{\circ} \mathrm{C}$, denatured for $10 \mathrm{~min}$ at $95^{\circ} \mathrm{C}$, and subjected to 45 amplification cycles consisting of annealing and extension at $60^{\circ} \mathrm{C}$ for $1 \mathrm{~min}$ followed by denaturation at $95^{\circ} \mathrm{C}$ for $15 \mathrm{~s}$. All TaqMan PCR data were captured using Sequence Detector software (Applied Biosystems). The template concentration in each reaction mixture was determined by comparison with a genespecific standard curve constructed using the cDNA of positive control samples and normalized by dividing the number of copies of the target gene by the number of copies of a housekeeping gene (glyceraldehyde-3-phosphate dehydrogenase (GAPDH) gene amplified using TaqMan rodent GAPDH control reagents; Applied Biosystems). To study the effect of rTRX-1 on gene expression of MIP-2 in GSM06 cells induced by $H$. felis infection, GSM06 cells were cultured in 12-well plates and pretreated with various concentrations of rTRX-1 $(0-5 \mu \mathrm{M})$ for $24 \mathrm{~h}$ and then incubated with or without $H$. felis (MOI 300:1) for another $6 \mathrm{~h}$ in the absence or presence of rTRX-1 $(0.05-5 \mu \mathrm{M})$ or $N$-acetylcysteine (NAC; $10 \mathrm{mM}$ ). Total RNA was extracted from GSM06 cells using ISOGEN reagent. Gene expression of MIP-2 was analyzed using TaqMan real-time PCR assay as described above.

\section{Cytotoxicity Assay}

Cytotoxicity assay was performed using the colorimetric assay reagent, TetraColor One (Seikagaku, Tokyo, Japan), according to the manufacturer's instructions. GSM06 cells were plated in a 96-well plate $\left(1 \times 10^{4}\right.$ cells/well $)$ and cultured for $24 \mathrm{~h}$. Cells were incubated with $1 \mathrm{mM} \mathrm{H}_{2} \mathrm{O}_{2}$ in the presence of $0,0.1,1,10$, and $50 \mu \mathrm{M}$ rTRX-1 for $5 \mathrm{~h}$. Then, $10 \mu \mathrm{l}$ of TetraColor One reagent was added to each well, and cells were incubated for another $2 \mathrm{~h}$. The absorbance at $450 \mathrm{~nm}$ was measured with a reference wavelength at $630 \mathrm{~nm}$ in the microplate reader.

\section{Chemotaxis Assay}

For the in vivo chemotaxis assay, a dorsal air pouch was created by injecting WT or TRX-1-TG mice (11-12 weeks old) with $5 \mathrm{ml}$ of air subcutaneously 7 and 3 days before the experiment as described previously. ${ }^{23}$ Then, $10 \mathrm{ng}$ of MIP-2 in $1 \mathrm{ml}$ of sterile pyrogen-free saline was injected into the air pouch. After $4 \mathrm{~h}$, the air pouch exudate was collected with $5 \mathrm{ml}$ PBS and the number of cells that migrated into the air pouch was determined using a NucleoCounter (ChemoMetec, Denmark). Effect of rTRX-1 on in vitro chemotaxis of murine whole bone marrow cells obtained from the femurs and human neutrophils was evaluated using 48-well micro-Boyden chambers (Neuro Probe, Bethesda, MD, USA) as described previously. ${ }^{23}$ Cell suspension with $100 \mathrm{ng} /$ $\mathrm{ml}(8.3 \mathrm{nM})$ of rTRX-1 was filled into the upper wells and $10 \mathrm{ng} / \mathrm{ml}$ of murine MIP-2 or human IL-8 was added to the bottom wells. After 2-hour incubation, the filters were stained with Diff-Quik dye (Kokusai Shiyaku, Kobe, Japan) and cells that migrated to the bottom wells were counted. Chemotactic activity was expressed as the average number of migrated cells in five oil immersion fields $(\times 200)$.

\section{Statistical Analysis}

The data were expressed as the mean \pm standard error (s.e.) or as the median (range) for the scoring system to assess gastritis. Mann-Whitney $U$-test was used where appropriate for statistical analysis. A $P$-value less than 0.05 was considered statistically significant.

\section{Results}

\section{Immunohistochemistry of Endogenous TRX-1 in Helicobacter-Induced Gastritis}

In uninfected WT mice, endogenous TRX-1 expression was detected predominantly in the parietal cells of the stomach (Figure 1c). At 2 months after $H$. felis inoculation, infected WT mice developed chronic active gastritis with moderate-to-severe inflammatory cell infiltration, loss of parietal and chief cells, and foveolar hyperplasia (Figure 1b). Abundant expression of TRX-1 was also detected in the remaining parietal cells of the inflamed stomach (Figure 1d).

\section{Prevention of $\boldsymbol{H}$. felis-Induced Gastritis in TRX-1-TG Mice}

In TRX-1-TG mice, expression of hTRX-1 protein in the stomach was confirmed by immunohistochemistry (Figure 2a) and Western blot analysis (Figure 2b). Although the expression of hTRX-1 was almost ubiquitous in gastric pit cells, parietal cells, and 

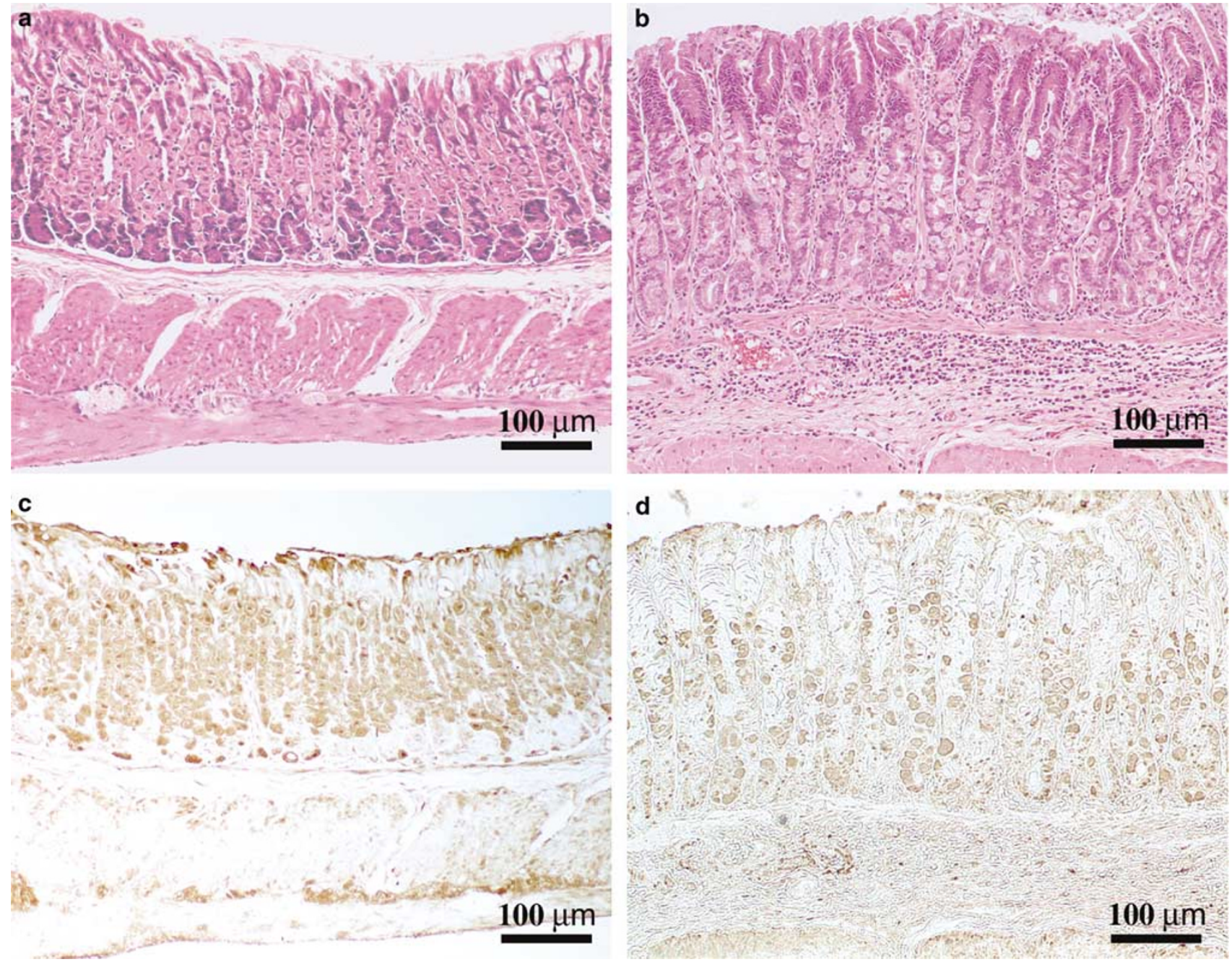

Figure 1 Representative histologic appearance of the stomach of $H$. felis-infected WT mice. (a) Uninfected WT mice. (b) H. felis-infected WT mice, showing severe infiltration of inflammatory cells, loss of parietal and chief cells, and foveolar hyperplasia (a and b: hematoxylin-eosin staining, original magnification $\times 200$ ). (c) Immunohistochemical staining of mTRX-1 in uninfected WT mice. Endogenous mTRX-1 was observed predominantly in parietal cells. (d) In H. felis-infected WT mice, mTRX-1 was detected in the remaining parietal cells of the inflamed gastric mucosa. (c and d: immunostaining, original magnification $\times 200$ ).

chief cells, the expression of hTRX-1 in parietal cells was stronger than in the other cell lineages. At 2 months after oral inoculation of $H$. felis, serum levels of anti- $\mathrm{H}$. felis antibodies were elevated in $12 / 20(60.0 \%)$ WT and 12/18 (66.7\%) TRX-1-TG mice (Figure 2c). There was no significant difference in the positive rate of anti-H. felis antibodies between WT and TRX-1-TG mice. In mice with no or little elevation of anti- $H$. felis antibodies, PCR products of the Helicobacter-specific gene in the gastric mucosa were negative and $H$. felis colonization was not observed by May-Giemsa staining of the stomach. In all of 12 TRX-1-TG mice with elevated anti- $H$. felis antibodies, PCR products and May-Giemsa staining were positive for $H$. felis (Figure 2d and e). In WT mice with high titer antibodies, however, there was little or no PCR Helicobacter-specific gene product (Figure 2d) and $H$. felis colonization was scarcely observed in the gastric mucosa, although all WT mice with positive

Figure 2 Assessment of $H$. felis infection in WT and TRX-1-TG mice. (a) Immunohistochemical staining of hTRX-1 of the gastric mucosa in WT and TRX-1-TG mice. Original magnification, $\times 200$. (b) Western blot analysis of human TRX-1 expression in the stomach. Gastric epithelial cells were isolated and separated into parietal cell-enriched fraction (I) and nonparietal cell-enriched fraction (II). Equivalent loading of each sample was verified by measuring $\alpha$-tubulin expression. (c) Serum levels of anti- $H$. felis antibodies were measured by ELISA 2 months after infection. Titers of anti- $H$. felis antibodies were elevated in both infected WT and TRX-1-TG mice. (d) PCR products of Helicobacter-specific gene in the stomach. Representative results analyzing 12 infected WT mice and 12 TRX-1-TG mice with positive anti- $H$. felis antibody are shown. PCR products were positive in all infected TRX-1-TG mice, but were negative or very little in infected WT mice. (e) May-Giemsa staining of the gastric mucosa in infected TRX-1-TG mice, showing colonization of $H$. felis. Arrows indicate H. felis. Original magnification, $\times 1000$. 
anti- $H$. felis antibodies had definite gastritis (Figure 1b). Thus, we used the $H$. felis-infected WT $(n=12)$ and TRX-1-TG mice $(n=12)$ for the following experiments ( $H$. felis-infected mice).
Macroscopically, the gastric mucosa was thickened in all infected WT mice 2 months after inoculation of $H$. felis, but not in all of 12 infected TG mice (Figure 3a). Histologically, all infected WT

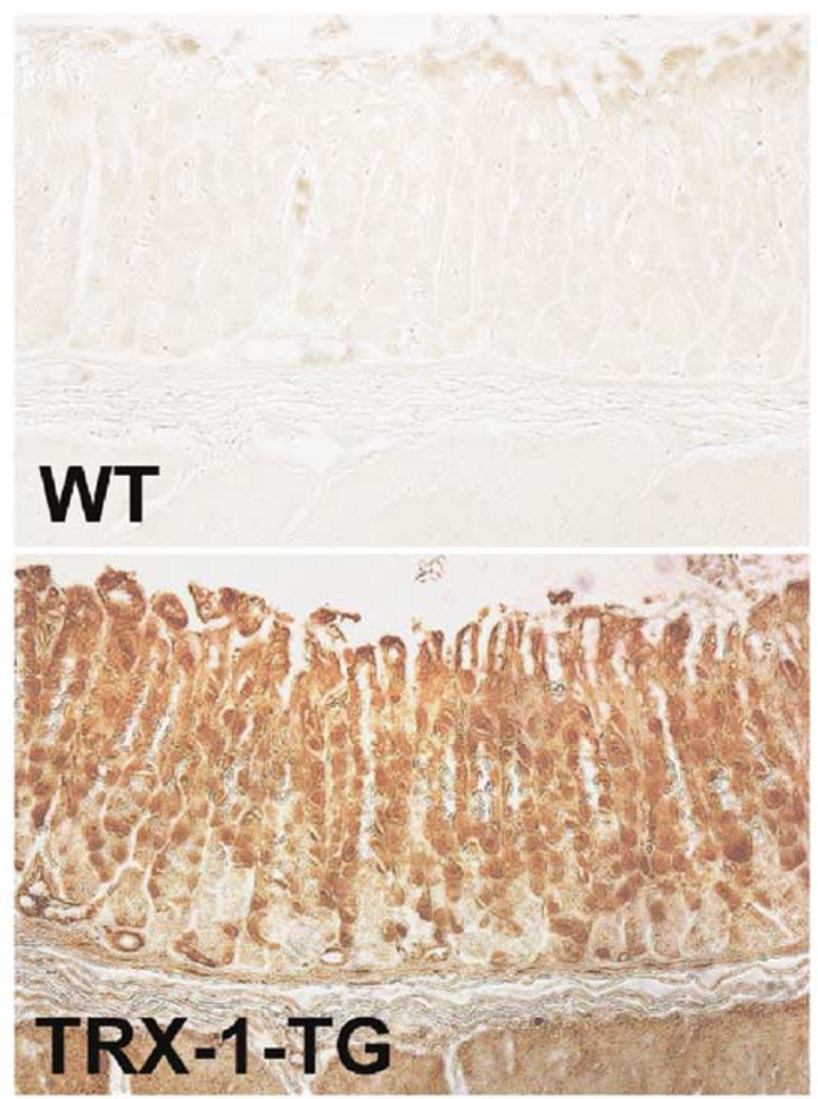

c 0

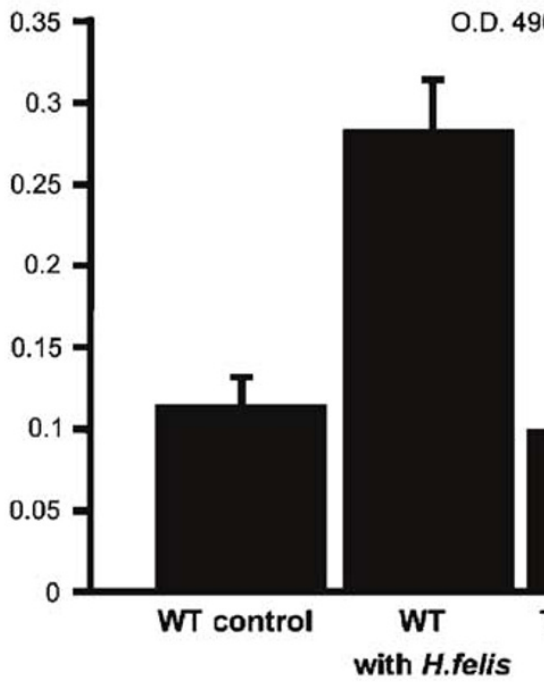

b

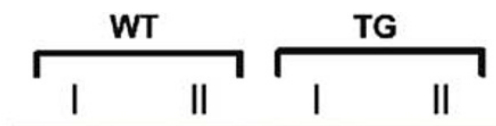

hTRX-1

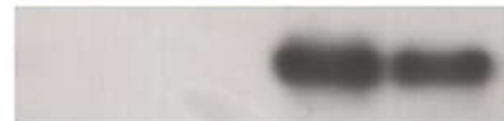

$\alpha$-tubulin 


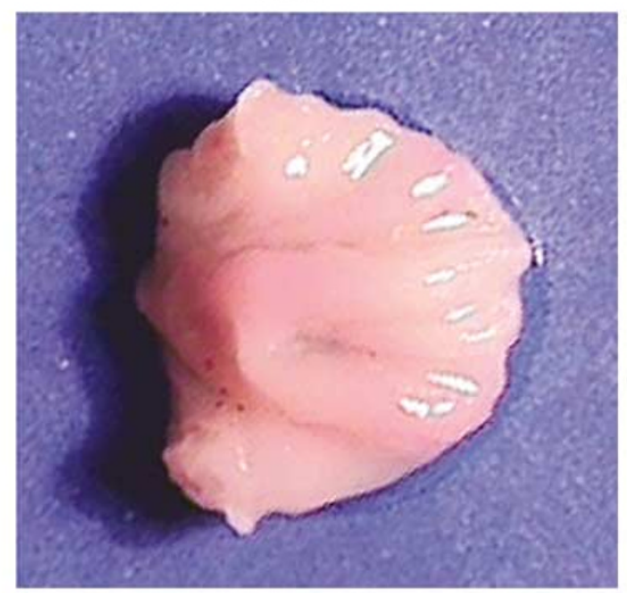

b

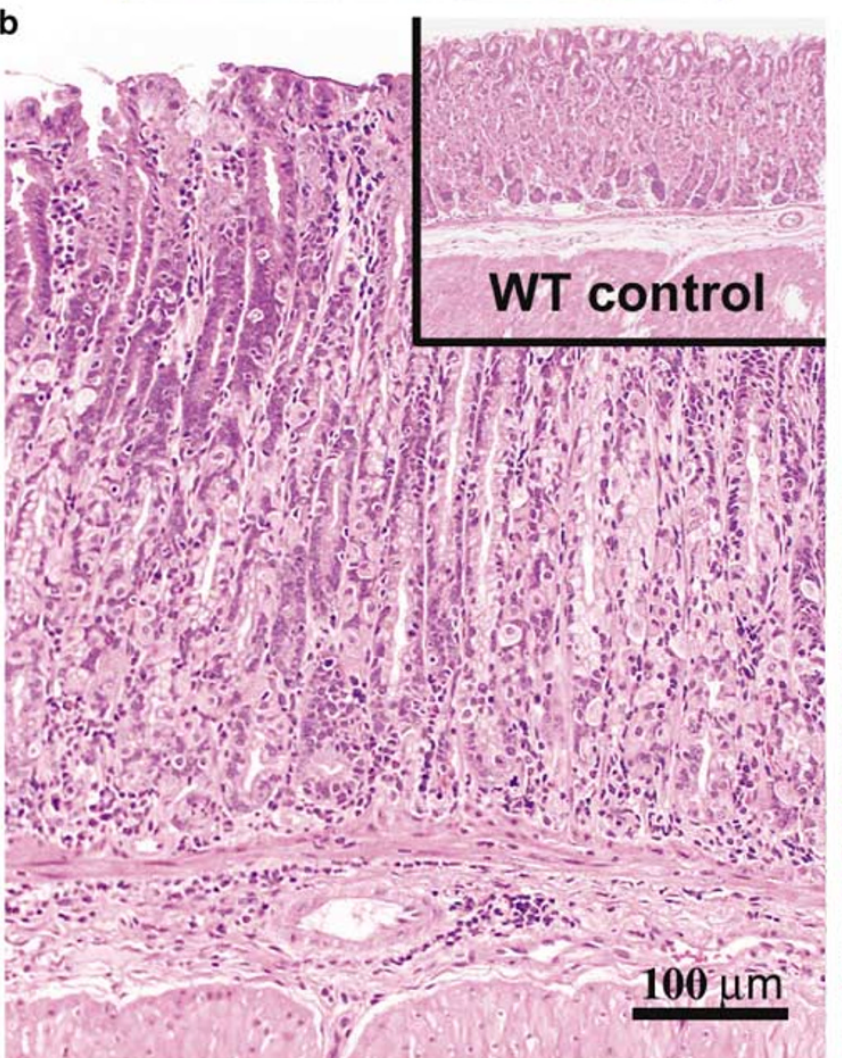

TRX-1-TG
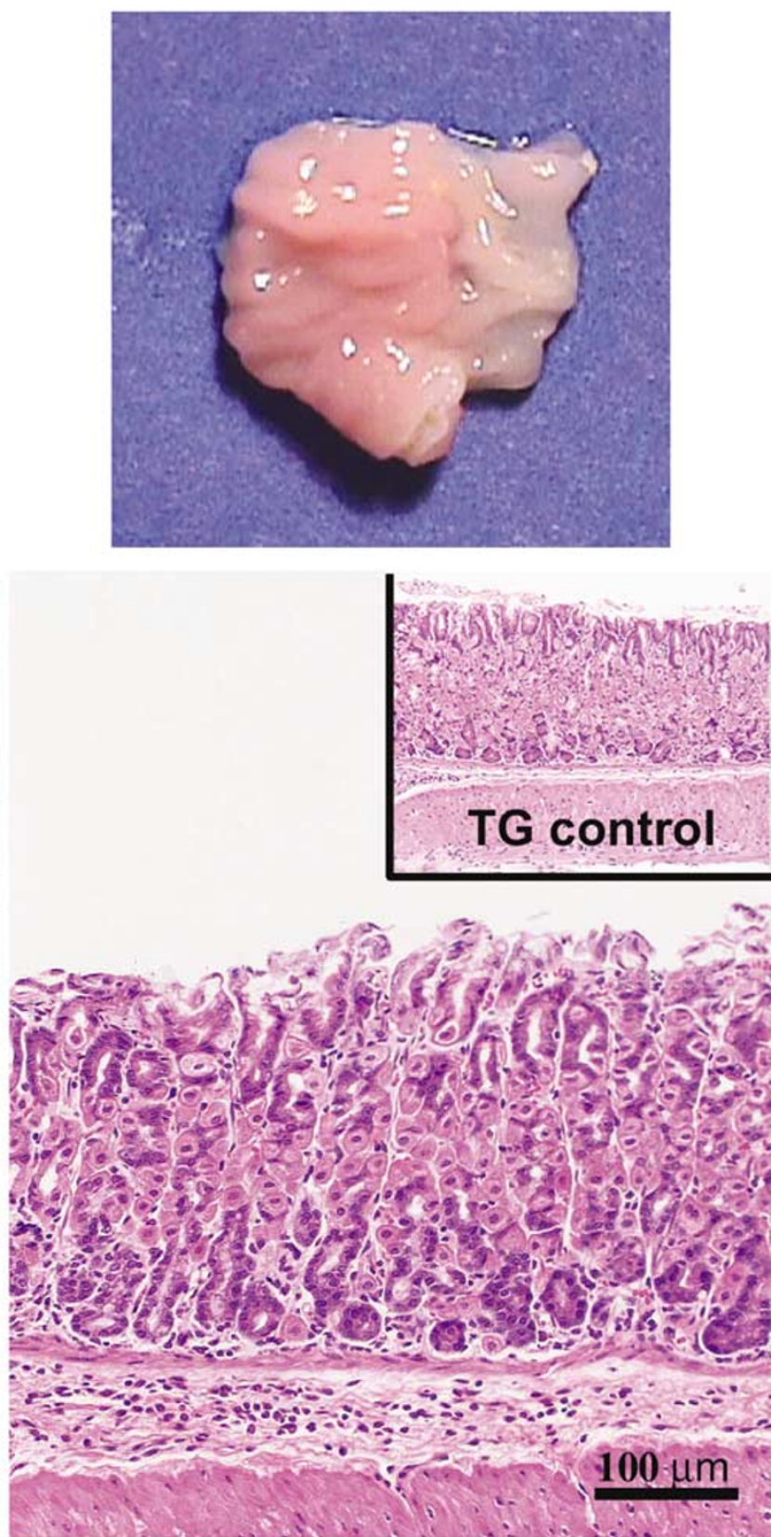

Figure 3 Macroscopic and microscopic appearance of the $H$. felis-infected stomachs of WT and TRX-1-TG mice. (a) Macroscopic appearance of the stomachs. The gastric mucosa was remarkably thickened in all infected WT mice but not in infected TRX-1-TG mice. (b) Histologically, the gastric mucosa of uninfected TRX-1-TG mice was the same as that of normal WT mice. H. felis-infected WT mice (left) developed moderate-to-severe gastritis with loss of parietal and chief cells and foveolar hyperplasia. Infected TRX-1-TG mice (right), however, had no gastritis or only mild gastritis with patchy infiltration of a few inflammatory cells. Original magnification, $\times 200$.

mice developed moderate-to-severe gastritis. In the deep portion of the glands, chief cells completely disappeared and were replaced by immature mucous cells as shown in Figure 3b. In contrast, infected TG mice had no sign of gastritis or had only localized patchy gastritis with a few inflammatory cells (Figure 3b). Scores for chronic inflammation, activity, and atrophic changes in infected TG mice were significantly lower than those in infected WT mice (Table 1).

\section{Analysis of Cytokine Expression in the Gastric Mucosa}

Proinflammatory cytokine messenger RNA (mRNA) profiles in the stomach of $H$. felis-infected WT and TRX-1-TG mice were assessed with TaqMan realtime PCR. At 2 months after infection, the expression of IL- $1 \beta$, TNF- $\alpha$, IL-7, and MIP-2 mRNAs was significantly increased in the stomach of infected WT mice $(P<0.05$ vs WT control). The increase 
in gene expression of IL- $1 \beta$ and TNF- $\alpha$ in infected TRX-1-TG mice was significantly less than that in infected WT mice $(P<0.05)$. In contrast, IL-7

Table 1 The degrees of gastritis in H. felis-infected WT and TRX-1-TG mice

\begin{tabular}{lccc}
\hline & $\begin{array}{c}\text { Infected } \\
\text { WT mice } \\
(\mathrm{n}=12)\end{array}$ & $\begin{array}{c}\text { Infected } \\
\text { TRX-1-TG } \\
\text { mice }(\mathrm{n}=12)\end{array}$ & P-value \\
\hline $\begin{array}{l}\text { Chronic } \\
\text { inflammation }\end{array}$ & $3(1-3)$ & $1(0-1)$ & $<0.01$ \\
$\begin{array}{l}\text { Activity } \\
\text { Atrophic changes }\end{array}$ & $2(1-3)$ & $1(0-1)$ & $<0.01$ \\
& $2(0-3)$ & $0(0-1)$ & $<0.01$ \\
\hline
\end{tabular}

Semiquantitative scoring of degrees of gastritis in infected WT and TRX-1-TG mice was carried out according to the histopathological criteria described in Materials and methods. Data are expressed as the median (range).

a
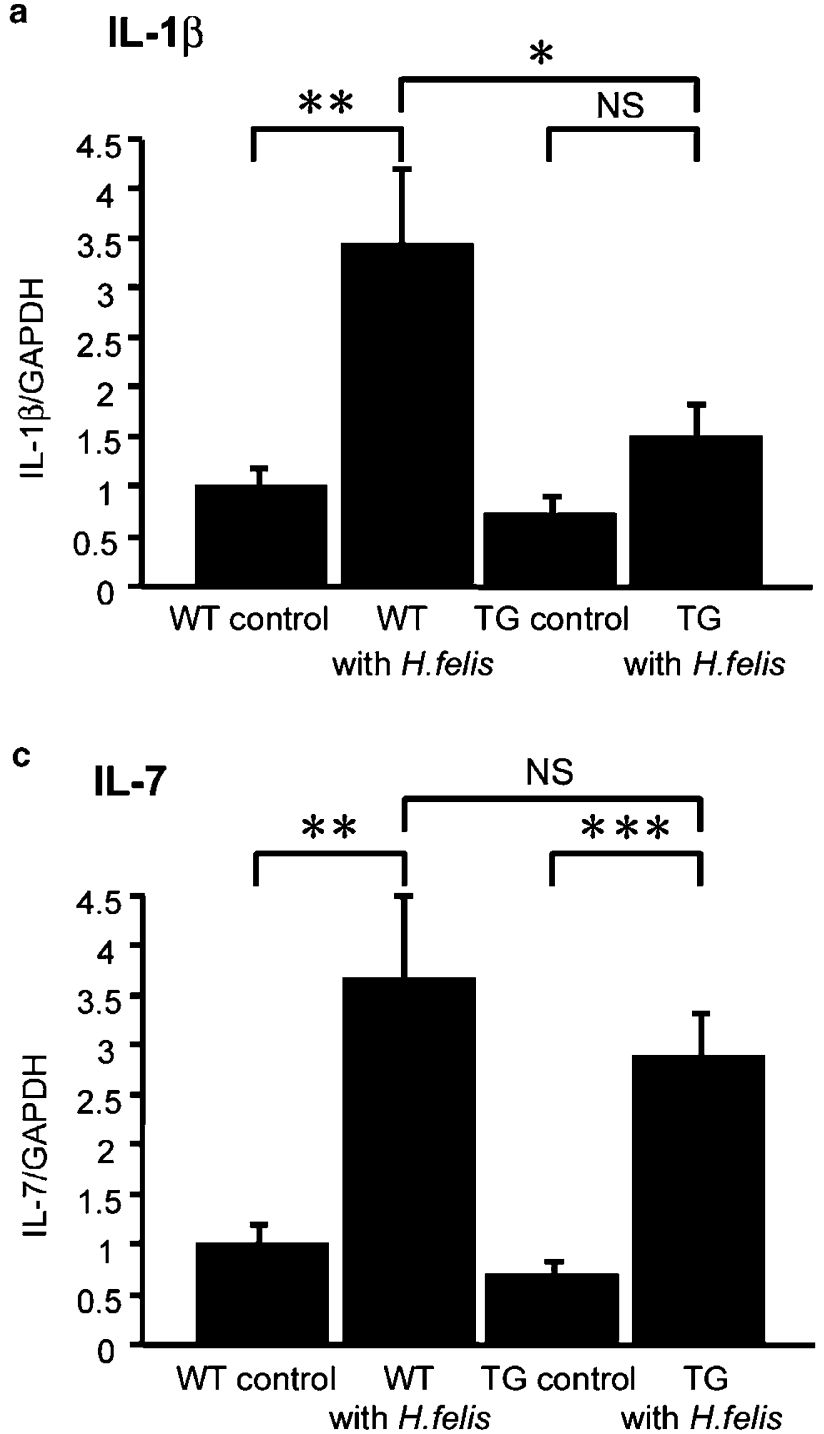

and MIP-2 mRNA levels in infected TRX-1-TG mice were not different from those in infected WT mice (Figure 4).

\section{Analysis of Oxidative Damage in the Gastric Mucosa}

8-OHdG, a major DNA base-modified product, is induced either by hydroxyl radical, singlet oxygen, or photodynamic action and is an established marker for oxidative stress. ${ }^{24,25}$ In $H$. felis-infected WT mice, nuclear immunostaining for 8-OHdG was observed predominantly in the deep portion of the hyperplastic gastric mucosa where inflammatory cell infiltration was stronger than other portion (Figure 5a-d). In contrast, there was no obvious staining for 8-OHdG in infected TRX-1-TG mice or in uninfected WT and TG mice.
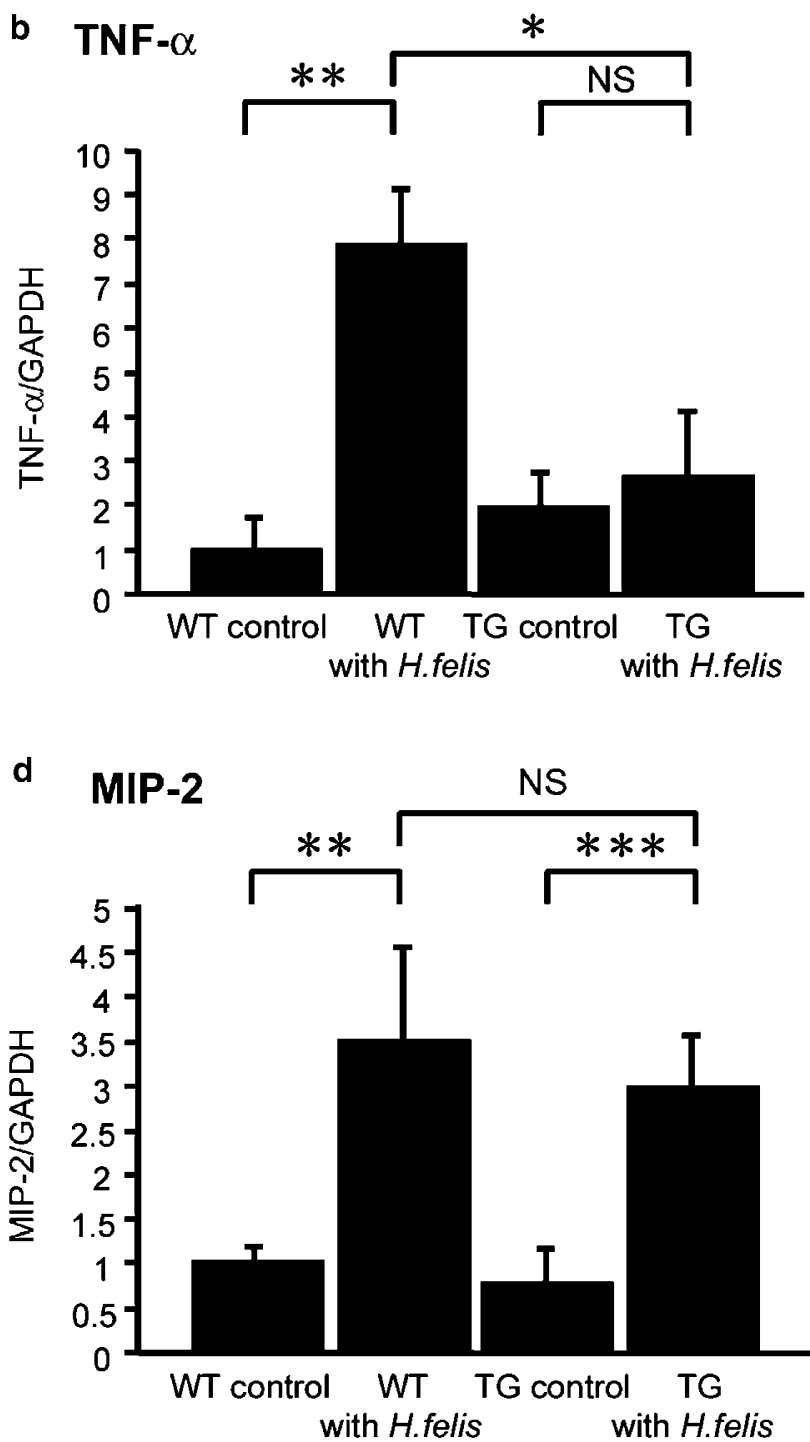

Figure 4 Gene expression of cytokines in the stomachs of WT and TRX-1-TG mice. (a) IL-1 $\beta$, (b) TNF- $\alpha$, (c) IL-7, and (d) MIP-2 mRNA levels in the stomach were measured by real-time PCR. mRNA levels (means \pm s.e.) relative to the mean of those in controls (uninfected WT mice) are shown. ${ }^{*} P<0.05$ vs WT with $H$. felis; ${ }^{*}{ }^{*} P<0.05$ vs WT control; ${ }^{*}{ }^{*} P<0.05$ vs TG control; NS $=$ not significant. 
WT

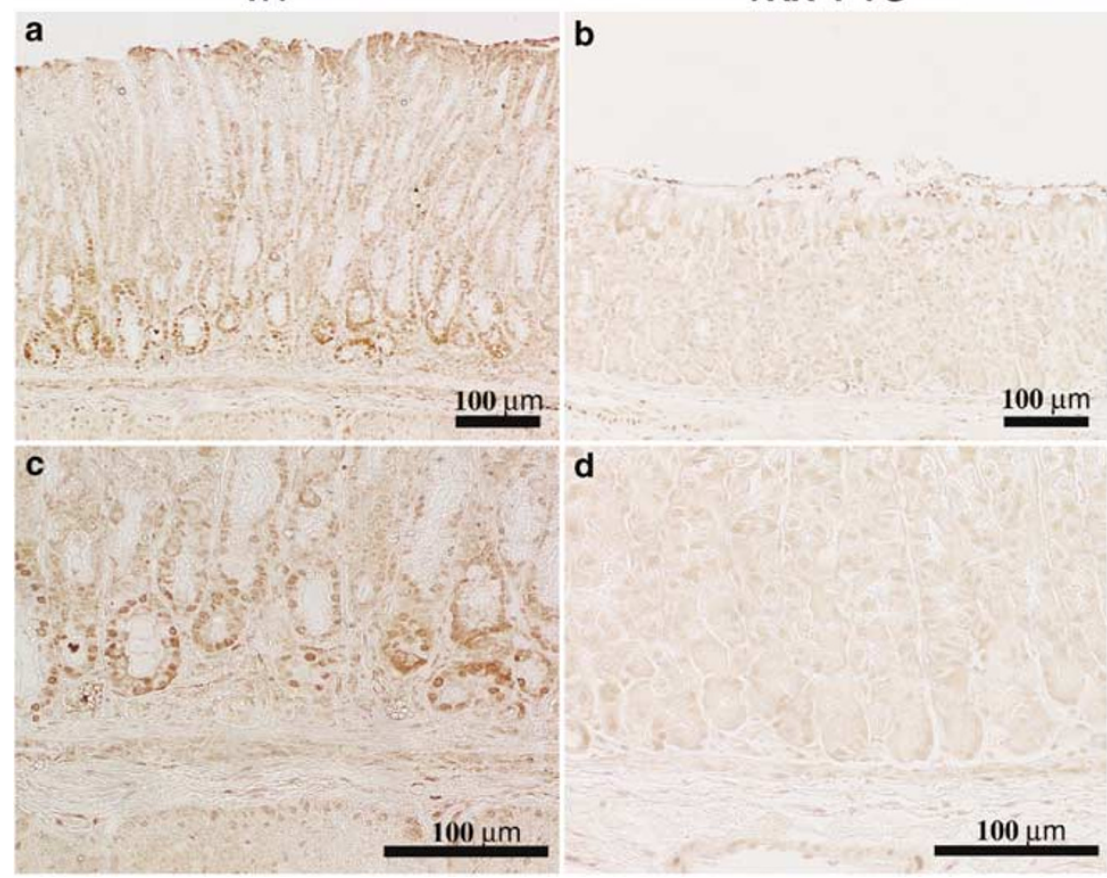

e

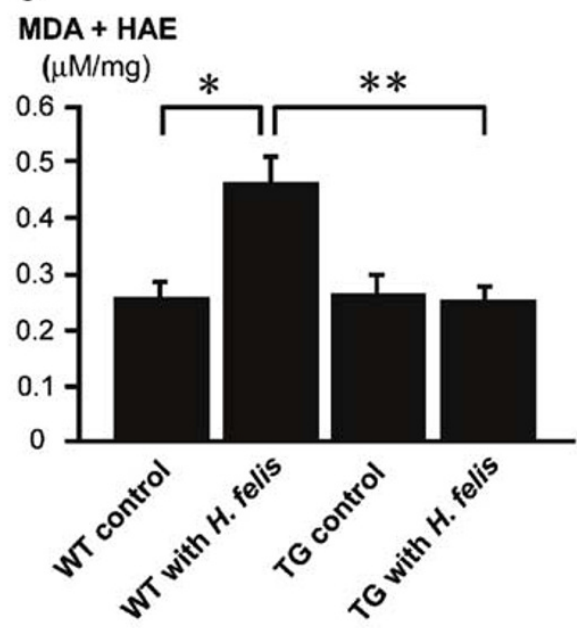

Figure 5 Oxidative stress in the gastric mucosa of WT and TRX-1-TG mice. Immunohistochemical staining of 8-OHdG. (a) $H$. felisinfected WT mice. Nuclear immunostaining for 8-OHdG was localized predominantly in the deep foveolar cells of hyperplastic gastric mucosa. Original magnification, $\times 200$. (b) $H$. felis-infected TRX-1-TG mice. There was no obvious staining for 8-OHdG in the gastric mucosa. Original magnification, $\times 200$. (c) High-power view of (a). Original magnification, $\times 400$. (d) High-power view of $(\mathbf{b})$. Original magnification, $\times 400$. (e) Total levels of MDA and HAE in the gastric mucosa of infected WT and TG mice. MDA and HAE levels were increased only in WT mice. ${ }^{*} P<0.05$ vs WT control; ${ }^{*} P<0.05$ vs WT with $H$. felis.

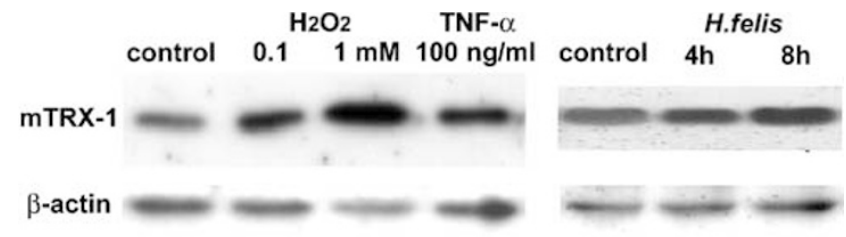

Figure 6 Western blot analysis of stress-induced mTRX-1 expression in GSM06 cells. Representative blots of mTRX-1 protein of three separate experiments are shown. GSM06 cells were incubated with $\mathrm{H}_{2} \mathrm{O}_{2}(0.1$ or $1 \mathrm{mM})$ for $4 \mathrm{~h}$, TNF- $\alpha(100 \mathrm{ng} / \mathrm{ml})$ for $4 \mathrm{~h}$, or $\mathrm{H}$. felis (MOI 150:1) for 4 and $8 \mathrm{~h}$. Equivalent loading of each sample was verified by measuring $\beta$-actin expression.

MDA and HAE, end products derived from peroxidation of polysaturated fatty acids and related esters, have been used as an indicator of lipid peroxidation. ${ }^{26}$ Tissue levels of MDA and HAE were significantly increased in the gastric mucosa of infected WT mice as compared with infected TRX1-TG mice or uninfected WT mice (Figure 5e). However, there were no significant differences among uninfected WT and TRX-1-TG mice, and infected TRX-1-TG mice.

\section{Induction of TRX-1 in Gastric Epithelial Cells In Vitro}

TRX-1 production in GSM06 cells was increased by stimulation with 0.1 and $1 \mathrm{mM} \mathrm{H}_{2} \mathrm{O}_{2}$ and
$100 \mathrm{ng} / \mathrm{ml}$ TNF- $\alpha$. H. felis (MOI 150:1) also enhanced endogenous TRX-1 production in GSM06 cells (Figure 6).

\section{Effects of TRX-1 on $\mathrm{H}_{2} \mathrm{O}_{2}$-Induced Cell Damage In Vitro}

Addition of rTRX-1 prevented $\mathrm{H}_{2} \mathrm{O}_{2}$-induced damage of GSM06 cells in a dose-dependent manner (0.1-50 $\mu \mathrm{M}$ ) (Figure 7a). Likewise, a dose-dependent protective effect of rTRX-1 on $\mathrm{H}_{2} \mathrm{O}_{2}$-induced DNA damage was observed by immunocytochemical staining for 8-OHdG (Figure 7b).

\section{Effects of TRX-1 on Neutrophil Migration}

In in vitro experiments, $H$. felis significantly enhanced MIP-2 gene expression in GSM06 cells $(P<0.05)$. Treatment with NAC significantly inhibited $H$. felis-induced MIP-2 mRNA expression. In contrast, upregulation of MIP-2 induced by $H$. felis was not suppressed, even in high concentrations of rTRX-1 (Figure 8). This is consistent with the increased MIP-2 mRNA expression in the gastric mucosa in $H$. felis-infected TRX-1-TG mice (Figure 4d). On the other hand, in the in vivo chemotaxis assay using the air pouch model, MIP-2induced leukocyte recruitment was suppressed in 
TRX-1-TG mice but not in WT mice (Figure 9a). Moreover, rTRX-1 significantly inhibited leukocyte migration induced by murine MIP-2 or human IL-8 in the in vitro chemotaxis assay using Boyden chambers (Figure 9b, c).

a O.D. $450 \mathrm{~nm}$
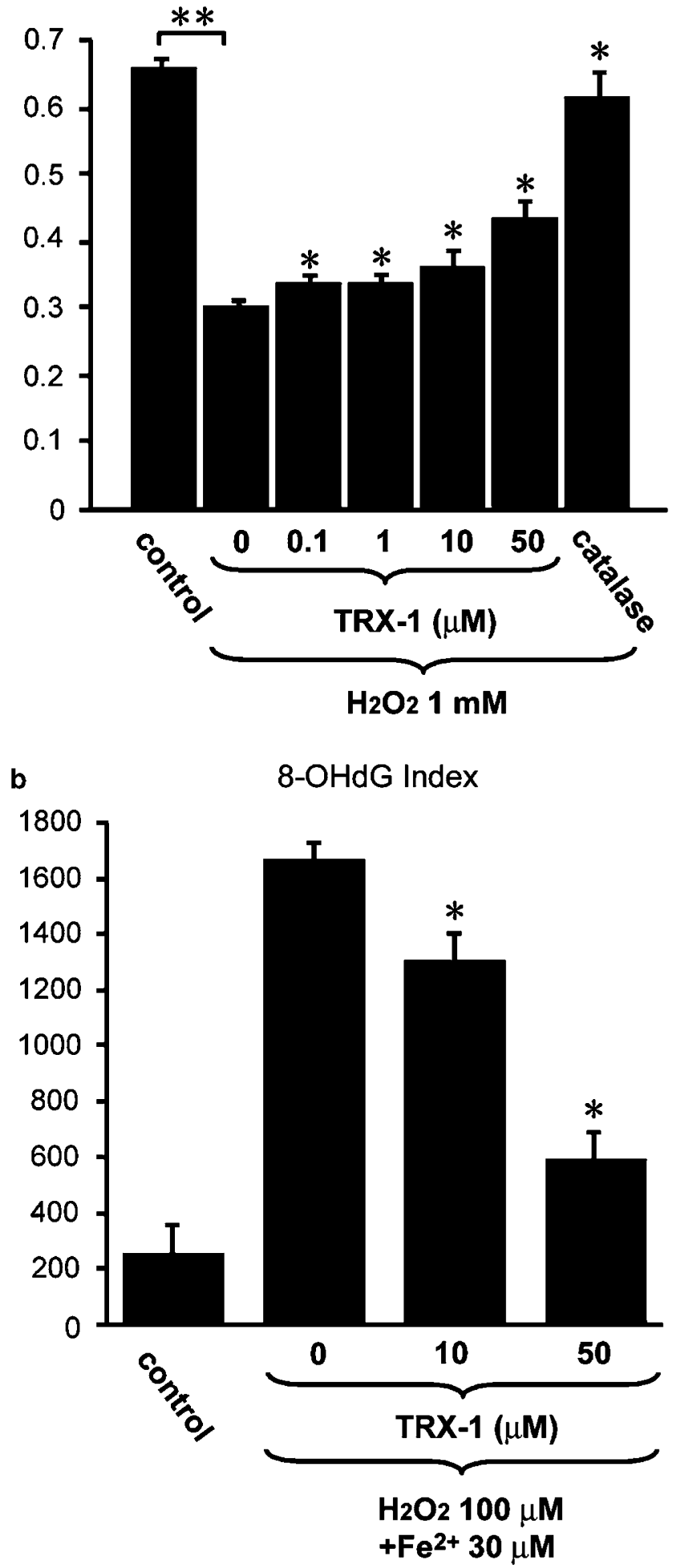

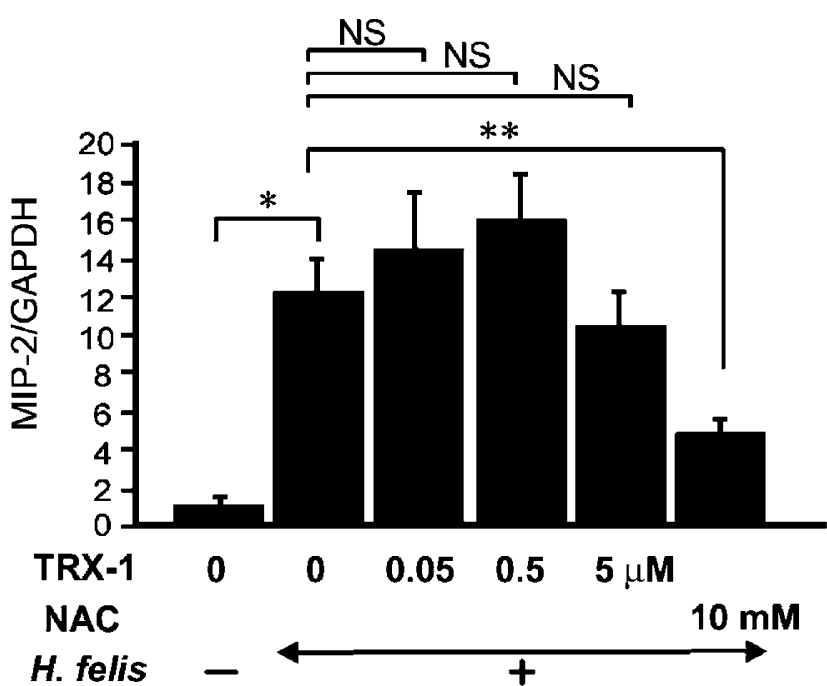

Figure 8 Effect of rTRX-1 on gene expression of MIP-2 in GSM06 cells. GSM06 cells were pretreated with various concentrations of rTRX-1 $(0-5 \mu \mathrm{M})$ for $24 \mathrm{~h}$ and then incubated with or without H. felis (MOI 300:1) for another $6 \mathrm{~h}$ in the same concentrations of rTRX-1 $(0-5 \mu \mathrm{M})$ or NAC $(10 \mathrm{mM}) .{ }^{*} P<0.05$ vs TRX $0 \mu \mathrm{M}$ without $H$. felis; ${ }^{* *} P<0.05$ vs TRX $0 \mu \mathrm{M}$ with $H$. felis; $\mathrm{NS}=$ not significant.

\section{Discussion}

Oxidative damage is pathophysiologically important in chronic gastritis, peptic ulcer disease, and gastric cancer. ${ }^{27,28}$ In $H$. pylori-infected chronic gastritis, active inflammation is accompanied by intense infiltration of inflammatory cells. Such inflammatory cells, especially neutrophils, are supposed to be the main source of oxygen-free radicals, which have an important role in gastric mucosal injury. In recent years, various groups have studied the effects of antioxidants, such as vitamin $\mathrm{C}$ and astaxanthin, on $H$. pylori-induced gastric diseases. ${ }^{29-31}$ Glutathione is a thiol-disulfide compound, and acts as the major endogenous antioxidant in oxidative stress. ${ }^{32} \mathrm{H}$. pylori infection reduces intracellular glutathione in gastric epithelial cells by generating ROS. ${ }^{33,34}$ Thus, oxidative stress is considered to result from the imbalance between prooxidants and antioxidants.

TRX-1 is a redox-active protein with a variety of biologic actions, including scavenging of ROS and regulating redox-sensitive molecules, such

Figure 7 Effect of rTRX-1 on $\mathrm{H}_{2} \mathrm{O}_{2}$-induced cell damage in vitro. (a) Effect of rTRX-1 on cell viability. GSM06 cells were treated with $\mathrm{H}_{2} \mathrm{O}_{2}(1 \mathrm{mM})$ in the absence or presence of rTRX-1 (0.1$50 \mu \mathrm{M})$ or catalase $(1000 \mathrm{U} / \mathrm{ml})$. Cell viability was measured with a colorimetric assay. Data are shown as means + s.e. of five experiments. ${ }^{*} P<0.05$ vs TRX $0 \mu \mathrm{M}$; ${ }^{* *} P<0.05$ vs control. (b) Effect of rTRX-1 on oxidative DNA damage. GSM06 cells were incubated with $\mathrm{H}_{2} \mathrm{O}_{2}(100 \mu \mathrm{M})$ plus $\mathrm{Fe}^{2+}(30 \mu \mathrm{M})$ in the absence or presence of rTRX-1 $(10$ or $50 \mu \mathrm{M})$. Treated cells were immunostained for 8-OHdG and subjected to densitometric analysis. Data are shown as means \pm s.e. of 8 -OHdG Index. ${ }^{*} P<0.05$ vs TRX $0 \mu \mathrm{M}$. 


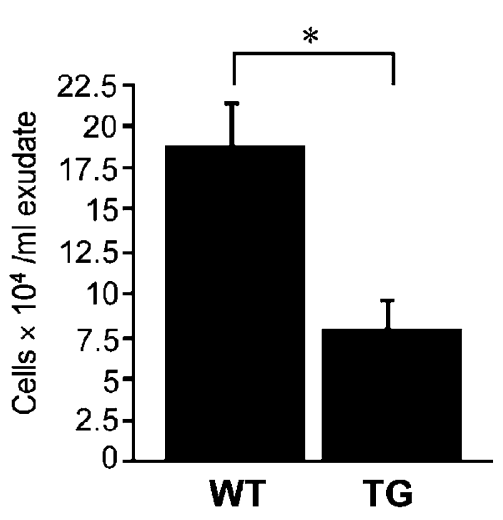

b

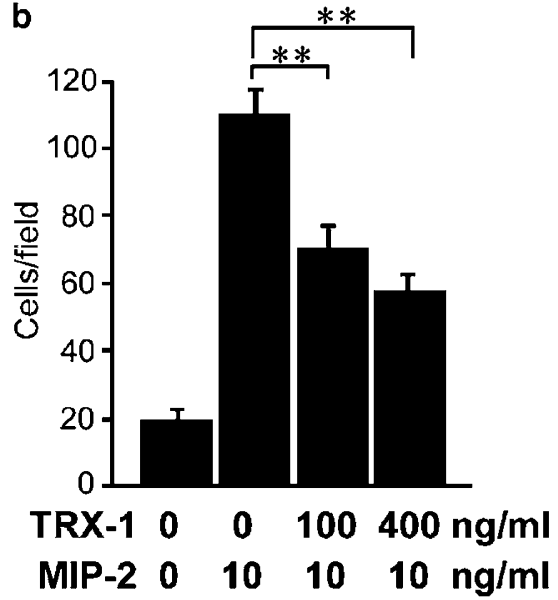

C

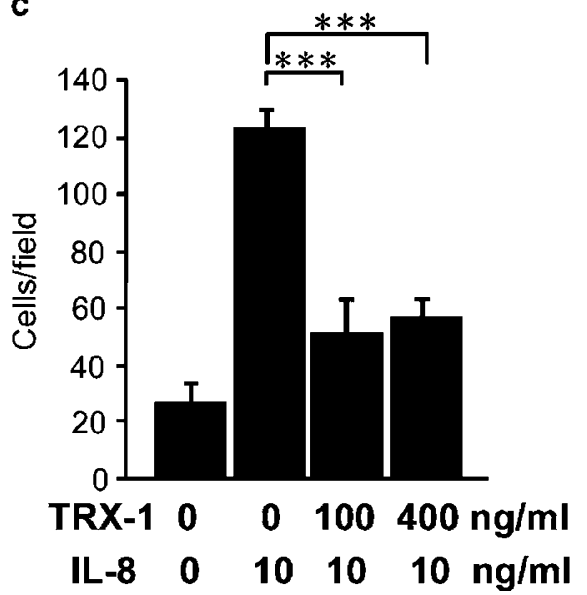

Figure 9 Effects of rTRX-1 on neutrophil chemotaxis in vivo and in vitro. (a) Chemotaxis induced by MIP-2 into the air pouch was significantly inhibited in TRX-1-TG mice. The number of migrated cells into the air pouch by MIP-2 was counted. ${ }^{*} P<0.05$; (b) rTRX-1 (100 or $400 \mathrm{ng} / \mathrm{ml}$ ) dose-dependently inhibited chemotaxis of murine bone marrow cells induced by murine MIP-2 (10 ng/ml) in vitro. ${ }^{*} P<0.05$ vs TRX $0 \mathrm{ng} / \mathrm{ml}$ and MIP-2 $10 \mathrm{ng} / \mathrm{ml}$. (c) rTRX-1 (100 or $400 \mathrm{ng} / \mathrm{ml}$ ) inhibited chemotaxis of human neutrophils induced by IL-8 (10 ng/ml) in vitro. ${ }^{* *} P<0.05$ vs TRX $0 \mathrm{ng} / \mathrm{ml}$ and IL-8 $10 \mathrm{ng} / \mathrm{ml}$.

as nuclear factor- $\kappa \mathrm{B}$, activator protein-1, and glucocorticoid receptors. ${ }^{10}$ Using TRX-1-TG mice, we demonstrated that TRX-1 suppressed Helicobacterinduced gastritis. Indeed, in TRX-1-TG mice, development of gastritis was markedly suppressed with little inflammatory cell infiltration. The reduced inflammation in TRX-1-TG mice was not due to the decrease in $H$. felis in the stomach because both PCR products and $H$. felis staining were all positive in the TRX-1-TG mice used in this study, and more clearly observed in TRX-1-TG mice than WT mice. These results are consistent with the previous reports that levels of $H$. felis colonization in infected mice with severe gastritis were lower than those in the nonresponder mouse strains. ${ }^{35,36}$ Thus, TRX-1 does not appear to eradicate H. felis, but suppresses subsequent inflammation in the gastric mucosa.

To evaluate the protective role of TRX-1 against oxidative cell damage, we used immunohistochemistry for 8-OHdG, a product of DNA oxidation, because 8-OHdG concentrations significantly correlate with the severity of $H$. pylori infection. ${ }^{8,37}$ Although 8-OHdG-positive cells were detected in the deep portion of the gastric mucosa of infected WT mice, there were no positive cells in TRX-1-TG mice, even in the portion with inflammatory cell infiltration. Likewise, the increment of MDA and HAE, end products of lipid peroxidation, was suppressed in infected TRX-1-TG mice. These results suggest that high levels of TRX-1 in infected TRX-1-TG mice protected gastric epithelial cells from oxidative damage by either inhibiting infiltration of ROS-producing cells or scavenging ROS produced in the gastric mucosa. In this regard, it is notable that in TRX-1-TG mice there are virtually no 8-OHdG-positive epithelial cells, in spite of slight inflammatory cell infiltration, suggesting a direct antioxidative effect of TRX-1 on epithelial cells. Therefore, we examined the direct effects of TRX-1 on epithelial cells in vitro, and found that administration of recombinant TRX-1 decreased oxidative cytotoxicity and DNA damage in GSM06 cells in a dose-dependent manner. Thus, the protective action of TRX-1 on gastric epithelial cells of $H$. felis-infected TRX-1-TG mice is exerted, at least in part, through its direct antioxidative effect on epithelial cells. Of note, abundant expression of endogenous TRX-1 was observed in parietal cell of WT mice. This may reflect the acid secretory function of parietal cells because glutathione, another major antioxidant, is abundantly present and is known to modulate acid secretion through thiol-disulfide interchange reactions. ${ }^{38}$ However, endogeneous TRX-1 could not effectively prevent the loss of parietal cells in the stomach of infected WT mice despite its abundant expression. This might be simply due to lower expression of TRX-1 in WT mice as compared with TRX-1-TG mice. However, the remaining parietal cells in the stomach of infected WT mice were negative for 8-OHdG immunostaining, suggesting that parietal cells are relatively resistant to oxidative stress compared with other gastric mucosal cells. Thus, parietal cell loss may be induced by other causes except for oxidative stress, such as direct contact with $H$. felis, ${ }^{39}$ inflammatory cytokines such as TNF- $\alpha,{ }^{40}$ Fas-FasL interaction, ${ }^{41}$ and antigastric autoantibodies. ${ }^{42}$ In this point, high levels of circulating TRX-1 in TG mice would be more important for cytoprotection through inhibition of leukocyte chemotaxis because the number of infiltrating inflammatory cells in the gastric mucosa was significantly reduced in infected TRX-1-TG mice and such cells are the sources of cytotoxic factors for gastric glandular cells. 
Interestingly, expression of hTRX-1 was also stronger in parietal cells of the stomach in TRX-1TG mice though it was ubiquitously expressed. One possible explanation is that overexpression of hTRX- 1 is driven by the $\beta$-actin promoter and its promoter activity is increased in parietal cells because microfilaments, made up of $\beta$-actin, are abundant to constitute tubulovesicular membranes and intracellular canaliculi for acid secretion. ${ }^{43}$ In addition, despite of the relatively lower expression of hTRX-1 in other cell lineages, the amount of hTRX-1 might be enough for cell protection against oxidative stress. Taken together, although endogenous TRX-1 was not enough to protect parietal cells in infected WT mice, overexpression of TRX-1 in infected TG mice was likely to protect gastric glandular cells by not only scavenging ROS but also reducing cytotoxic factors resulting from infiltrating inflammatory cells.

To further elucidate the role of TRX-1 in the pathophysiology of Helicobacter-induced gastritis, we examined gene expression of several cytokines in the $H$. felis-infected stomach of TRX-1-TG mice. Similar to $H$. pylori infection in human gastric mucosa,${ }^{44} \mathrm{H}$. felis infection markedly enhanced gene expression of IL- $1 \beta$, TNF- $\alpha$, IL-7, and MIP-2, a mouse counterpart for human IL-8, ${ }^{45}$ in the stomach of WT mice. Although IL- $1 \beta$ and TNF- $\alpha$ mRNA expression was significantly lower in TRX-1-TG mice than in WT mice, gene expression of IL-7 and MIP-2 was not different from WT mice. The reason for such different gene expression of IL- $1 \beta$ and TNF- $\alpha$ versus that of IL-7 and MIP-2 in TRX-1-TG mice is not known. However, one possibility is that IL-1 $\beta$ and TNF- $\alpha$ are mainly produced by inflammatory cells infiltrating the mucosa, whereas both IL-7 and MIP-2 are produced by gastric epithelial cells in Helicobacter infection. ${ }^{44,46}$ Indeed, we previously demonstrated that $H$. felis infection induces IL-7 production mainly in gastric epithelial cells in mice. ${ }^{14}$ Moreover, in the present study, H. felis directly stimulated MIP-2 gene expression in GSM06 cells, a murine gastric epithelial cell line. Thus, it is possible that although the decrease in inflammatory cell infiltration resulted in reduced expression of IL- $1 \beta$ and TNF- $\alpha$ in the stomach of $H$. felis-infected TRX-1-TG mice, neither IL-7 nor MIP-2 expression in epithelial cells was influenced by TRX-1. Supporting this idea, TRX-1 had no direct inhibitory effect on $\mathrm{H}$. felis-induced gene expression of MIP-2 in GSM06 cells in vitro. Thus, the reduced inflammation of the gastric mucosa observed in TRX-1-TG mice does not involve decreased expression of IL-7 or MIP-2.

TRX is known to be a chemoattractant like IL-8 and monocyte chemoattractant protein-1 (MCP-1), which attracts neutrophils, and monocytes and memory $\mathrm{T}$ cells, respectively. ${ }^{23}$ However, few inflammatory cells infiltrated into the stomach in $H$. felis-infected TRX-1-TG mice despite high levels of gastric mucosal MIP-2, a murine equivalent to
IL-8, suggesting that TRX-1 overexpression inhibited neutrophil migration. Our findings that TRX-1 significantly inhibited leukocyte migration induced by murine MIP-2 in vivo and by murine MIP-2 or human IL-8 in vitro support such a speculation. Intravenous injection of IL-8 has been shown to inhibit polymorphonuclear cell accumulation in response to local injection of IL-8. ${ }^{47,48}$ Leukocyte migration is impaired in transgenic mice overexpressing human IL-8 or MCP-1. ${ }^{49,50}$ Therefore, high levels of circulating TRX-1 may similarly decrease the ability of leukocytes to migrate efficiently to a site of infection, either by neutralization of a chemoattractant gradient or receptor downregulation. However, downregulation of MIP2 receptor (CXCR2) by TRX-1 is unlikely because we previously demonstrated that TRX-1 failed to suppress CXCR2 expression increased in bone marrow cells of experimental autoimmune myocarditis mice. ${ }^{51}$ Alternatively, dose-dependent inhibition of chemotaxis suggests the neutralization of a chemoattractant gradient by TRX-1.

In conclusion, the present study clearly demonstrated that TRX-1 suppresses Helicobacter-induced gastritis by inhibiting neutrophil chemotaxis and scavenging ROS. TRX-1 may play an important role in the host defense mechanism against the ROS-related gastric mucosal injury including Helicobacter infection.

\section{Acknowledgements}

We thank A Yamada and H Kohda for their expert technical support. This work was supported by The Shimizu Foundation for the Promotion of Immunology Research.

\section{References}

1 Suerbaum S, Michetti P. Helicobacter pylori infection. N Engl J Med 2002;347:1175-1186.

2 Prinz C, Hafsi N, Voland P. Helicobacter pylori virulence factors and the host immune response: implications for therapeutic vaccination. Trends Microbiol 2003;11:134-138.

3 Fujikawa A, Shirasaka D, Yamamoto S, et al. Mice deficient in protein tyrosine phosphatase receptor type $\mathrm{Z}$ are resistant to gastric ulcer induction by VacA of Helicobacter pylori. Nat Genet 2003;33:375-381.

4 Higashi H, Tsutsumi R, Muto S, et al. SHP-2 tyrosine phosphatase as an intracellular target of Helicobacter pylori CagA protein. Science 2002;295:683-686.

5 Mimuro H, Suzuki T, Tanaka J, et al. Grb2 is a key mediator of Helicobacter pylori CagA protein activities. Mol Cell 2002;10:745-755.

6 Yoshikawa T, Naito Y. The role of neutrophils and inflammation in gastric mucosal injury. Free Radic Res 2001;33:785-794.

7 Ding SZ, O'Hara AM, Denning TL, et al. Helicobacter pylori and $\mathrm{H}_{2} \mathrm{O}_{2}$ increase AP endonuclease-1/redox 
factor-1 expression in human gastric epithelial cells. Gastroenterology 2004;127:845-858.

8 Pignatelli B, Bancel B, Plummer M, et al. Helicobacter pylori eradication attenuates oxidative stress in human gastric mucosa. Am J Gastroenterol 2001;96: 1758-1766.

9 Nakamura H, Nakamura K, Yodoi J. Redox regulation of cellular activation. Annu Rev Immunol 1997;15: 351-369.

10 Hirota K, Nakamura H, Masutani $\mathrm{H}$, et al. Thioredoxin superfamily and thioredoxin-inducing agents. Ann N Y Acad Sci 2002;957:189-199.

11 Takagi Y, Mitsui A, Nishiyama A, et al. Overexpression of thioredoxin in transgenic mice attenuates focal ischemic brain damage. Proc Natl Acad Sci USA 1999;96:4131-4136.

12 Shioji K, Kishimoto C, Nakamura H, et al. Overexpression of thioredoxin-1 in transgenic mice attenuates adriamycin-induced cardiotoxicity. Circulation 2002;106:1403-1409.

13 Okuyama H, Nakamura H, Shimahara Y, et al. Overexpression of thioredoxin prevents acute hepatitis caused by thioacetamide or lipopolysaccharide in mice. Hepatology 2003;37:1015-1025.

14 Ohana M, Okazaki K, Oshima C, et al. A critical role for IL-7R signaling in the development of Helicobacter felis-induced gastritis in mice. Gastroenterology 2001; 121:329-336.

15 Sugiyama N, Tabuchi Y, Horiuchi T, et al. Establishment of gastric surface mucous cell lines from transgenic mice harboring temperature-sensitive simian virus 40 large T-antigen gene. Exp Cell Res 1993;209: 382-387.

16 Tabuchi Y, Sugiyama N, Horiuchi T, et al. Biological characterization of gastric surface mucous cell line GSM06 from transgenic mice harboring temperaturesensitive simian virus 40 large T-antigen gene. Digestion 1996;57:141-148.

17 Fukuma K, Sakaguchi S, Kuribayashi K, et al. Immunologic and clinical studies on murine experimental autoimmune gastritis induced by neonatal thymectomy. Gastroenterology 1988;94:274-283.

18 Fukui T, Okazaki K, Tamaki H, et al. Immunogenetic analysis of gastric MALT lymphoma-like lesions induced by Helicobacter pylori infection in neonatally thymectomized mice. Lab Invest 2004;84:485-492.

19 Sakagami T, Dixon M, O’Rourke J, et al. Atrophic gastric changes in both Helicobacter felis and Helicobacter pylori infected mice are host dependent and separate from antral gastritis. Gut 1996;39: 639-648.

20 Oshima C, Okazaki K, Matsushima Y, et al. Induction of follicular gastritis following postthymectomy autoimmune gastritis in Helicobacter pylori-infected $\mathrm{BALB} / \mathrm{c}$ mice. Infect Immun 2000;68:100-106.

21 Riley LK, Franklin CL, Hook Jr RR, et al. Identification of murine helicobacters by PCR and restriction enzyme analyses. J Clin Microbiol 1996;34:942-946.

22 Toyokuni S, Tanaka T, Hattori Y, et al. Quantitative immunohistochemical determination of 8-hydroxy-2' deoxyguanosine by a monoclonal antibody N45.1: its application to ferric nitrilotriacetate-induced renal carcinogenesis model. Lab Invest 1997;76:365-374.

23 Bertini R, Howard OM, Dong HF, et al. Thioredoxin, a redox enzyme released in infection and inflammation, is a unique chemoattractant for neutrophils, monocytes, and T cells. J Exp Med 1999;189:1783-1789.
24 Witherell HL, Hiatt RA, Replogle M, et al. Helicobacter pylori infection and urinary excretion of 8-hydroxy-2deoxyguanosine, an oxidative DNA adduct. Cancer Epidemiol Biomarkers Prev 1998;7:91-96.

25 Toyokuni S. Reactive oxygen species-induced molecular damage and its application in pathology. Pathol Int 1999;49:91-102.

26 Esterbauer H, Schaur RJ, Zollner H. Chemistry and biochemistry of 4-hydroxynonenal, malonaldehyde and related aldehydes. Free Radic Biol Med 1991;11: 81-128.

27 Felley CP, Pignatelli B, Van Melle GD, et al. Oxidative stress in gastric mucosa of asymptomatic humans infected with Helicobacter pylori: effect of bacterial eradication. Helicobacter 2002;7:342-348.

28 Santra A, Chowdhury A, Chaudhuri S, et al. Oxidative stress in gastric mucosa in Helicobacter pylori infection. Indian J Gastroenterol 2000;19:21-23.

29 Serafini M, Bellocco R, Wolk A, et al. Total antioxidant potential of fruit and vegetables and risk of gastric cancer. Gastroenterology 2002;123:985-991.

30 Bennedsen M, Wang X, Willen R, et al. Treatment of $H$. pylori infected mice with antioxidant astaxanthin reduces gastric inflammation, bacterial load and modulates cytokine release by splenocytes. Immunol Lett 1999;70:185-189.

31 Waring AJ, Drake IM, Schorah CJ, et al. Ascorbic acid and total vitamin $\mathrm{C}$ concentrations in plasma, gastric juice, and gastrointestinal mucosa: effects of gastritis and oral supplementation. Gut 1996;38: 171-176.

32 Meister A. Glutathione-ascorbic acid antioxidant system in animals. J Biol Chem 1994;269:93979400.

33 Beil W, Obst B, Sewing KF, et al. Helicobacter pylori reduces intracellular glutathione in gastric epithelial cells. Dig Dis Sci 2000;45:1769-1773.

34 Shirin H, Pinto JT, Liu LU, et al. Helicobacter pylori decreases gastric mucosal glutathione. Cancer Lett 2001;164:127-133.

35 Eaton KA, Mefford M, Thevenot T. The role of T cell subsets and cytokines in the pathogenesis of Helicobacter pylori gastritis in mice. J Immunol 2001;166: 7456-7461.

36 Roth KA, Kapadia SB, Martin SM, et al. Cellular immune responses are essential for the development of Helicobacter felis-associated gastric pathology. J Immunol 1999;163:1490-1497.

37 Smoot DT, Elliott TB, Verspaget HW, et al. Influence of Helicobacter pylori on reactive oxygen-induced gastric epithelial cell injury. Carcinogenesis 2000;21: 2091-2095.

38 Olson CE, Soll AH, Kaplowitz N. Modulating effect of thiol-disulfide status on [14C]aminopyrine accumulation in the isolated parietal cell. J Biol Chem 1985;260: 8020-8025.

39 Neu B, Randlkofer P, Neuhofer M, et al. Helicobacter pylori induces apoptosis of rat gastric parietal cells. Am J Physiol Gastrointest Liver Physiol 2002;283: G309-G318.

40 Neu B, Puschmann AJ, Mayerhofer A, et al. TNF-alpha induces apoptosis of parietal cells. Biochem Pharmacol 2003;65:1755-1760.

41 Houghton JM, Bloch LM, Goldstein M, et al. In vivo disruption of the fas pathway abrogates gastric growth alterations secondary to Helicobacter infection. J Infect Dis 2000;182:856-864. 
42 Faller G, Kirchner T. Role of antigastric autoantibodies in chronic Helicobacter pylori infection. Microsc Res Tech 2000;48:321-326.

43 Forte JG, Ly B, Rong Q, et al. State of actin in gastric parietal cells. Am J Physiol 1998;274:C97-C104.

44 Yamaoka Y, Kita M, Kodama T, et al. Helicobacter pylori cagA gene and expression of cytokine messenger RNA in gastric mucosa. Gastroenterology 1996;110: 1744-1752.

45 Tekamp-Olson P, Gallegos C, Bauer D, et al. Cloning and characterization of cDNAs for murine macrophage inflammatory protein 2 and its human homologues. J Exp Med 1990;172:911-919.

46 Obonyo M, Guiney DG, Harwood J, et al. Role of gamma interferon in Helicobacter pylori induction of inflammatory mediators during murine infection. Infect Immun 2002;70:3295-3299.

47 Hechtman DH, Cybulsky MI, Fuchs HJ, et al. Intravascular IL-8. Inhibitor of polymorphonuclear leuko- cyte accumulation at sites of acute inflammation. J Immunol 1991;147:883-892.

48 Ley K, Baker JB, Cybulsky MI, et al. Intravenous interleukin-8 inhibits granulocyte emigration from rabbit mesenteric venules without altering L-selectin expression or leukocyte rolling. J Immunol 1993;151: 6347-6357.

49 Simonet WS, Hughes TM, Nguyen HQ, et al. Long-term impaired neutrophil migration in mice overexpressing human interleukin-8. J Clin Invest 1994;94:1310-1319.

50 Rutledge BJ, Rayburn H, Rosenberg R, et al. High level monocyte chemoattractant protein-1 expression in transgenic mice increases their susceptibility to intracellular pathogens. J Immunol 1995;155:48384843.

51 Liu W, Nakamura H, Shioji K, et al. Thioredoxin-1 ameliorates myosin-induced autoimmune myocarditis by suppressing chemokine expressions and leukocyte chemotaxis in mice. Circulation 2004;110:1276-1283. 